ASTHMA

\title{
Association of body mass with pulmonary function in the Childhood Asthma Management Program (CAMP)
}

\author{
K G Tantisira, A A Litonjua, S T Weiss, A L Fuhlbrigge, for the Childhood Asthma Management \\ Program Research Group
}

See end of article for authors' affiliations

......................

Correspondence to: Dr K G Tantisira, Channing Laboratory, 181

Longwood Avenue, Boston, MA 02115, USA rekgt@channing.

harvard.edu

Revised version received 4 June 2003

Accepted for publication 11 July 2003
Background: While increases in body mass index (BMI) have been associated with the incidence and prevalence of asthma, the mechanisms behind this association are unclear.

Methods: We hypothesised that BMI would be independently associated with measures of asthma severity in a population of children with mild to moderate asthma enrolled in the Childhood Asthma Management Program (CAMP). A multivariable baseline cross sectional analysis of BMI with our outcomes of interest was performed.

Results: BMI was generally not associated with symptoms, nor was it associated with atopy. While BMI was positively associated with the methacholine concentration that causes a $20 \%$ fall in forced expiratory volume in 1 second $\left(\mathrm{PC}_{20} \mathrm{FEV}_{1}\right)$, this association did not persist after adjustment for $\mathrm{FEV} \mathrm{F}_{1}$. Increasing $\mathrm{BMI}$ was associated with increasing $\mathrm{FEV}_{1}(\beta=0.006 \mathrm{l}, 95 \% \mathrm{Cl}(0.001$ to 0.01$))$ and forced vital capacity (FVC) $(\beta=0.012 \mathrm{I}, 95 \% \mathrm{Cl}(0.007$ to 0.017$))$. However, decrements in the $\mathrm{FEV} / \mathrm{FVC}$ ratio were noted with increasing $\mathrm{BMI}(\beta=-0.242,95 \% \mathrm{Cl}(-0.118$ to -0.366$))$. Thus, an increase in BMI of 5 units was associated with a decrease in $\mathrm{FEV}_{1} / \mathrm{FVC}$ of over $1 \%$.

Conclusions: Although the association of $\mathrm{FEV}_{1}$ and $\mathrm{FVC}$ with $\mathrm{BMI}$ did not support our initial hypothesis, the decrease noted in the $\mathrm{FEV}_{1} / \mathrm{FVC}$ ratio has potential relevance in the relationship between $\mathrm{BMI}$ and asthma severity.
O ver the past 20 years the incidence and prevalence of obesity among the youth in America have steadily increased. The most recent data from the Centers for Disease Control's (CDC) Third National Health and Nutrition Examination Survey (NHANES III) revealed a prevalence of obesity-defined as a body mass index (BMI) in excess of $95 \%$ of the age specific distribution-of $14 \%$ in children aged 6-11 surveyed between 1988 and 1994. ${ }^{1}$ In comparison, NHANES II, conducted between 1976 and 1980, found a prevalence of obesity of $7.6 \%$ for the same population. This has been accompanied by a similar rise in the associated rates of asthma. The CDC self-reported prevalence of asthma in children aged 5-14 rose from 42.8 per 1000 in 1980 to 74.4 per 1000 in $1994 .^{2}$

Given the dramatic rise in the prevalence of obesity and asthma, it is not surprising that there has been an increasing body of literature on the association between BMI and asthma. In the paediatric population, increases in BMI have been associated with an increased incidence ${ }^{3}$ and prevalence ${ }^{4-7}$ of asthma. At the extremes of BMI, a similar increase in the prevalence of asthma has been noted with overweight ${ }^{8}$ and obesity in children. ${ }^{9}$ Furthermore, this relationship may be influenced by sex. While greater preadolescent asthma incidence ${ }^{10}$ and severity ${ }^{11} 12$ have generally been associated with boys, the obesity/asthma relationship may be a phenomenon of girls. The risk of prevalent asthma has been found to be higher in obese girls than non-obese girls or boys of any body mass in cross sectional studies of German children. ${ }^{13}$ Additionally, increases in BMI have been associated with incident wheezing, peak flow variability, and bronchodilator response in girls of school age but not boys. ${ }^{14}$

While the association between increased BMI and asthma is well documented, the mechanisms behind this association in children are unclear. We hypothesised that BMI would be independently related to asthma severity as reflected by pulmonary function, symptom outcomes, and relevant intermediate phenotypes in asthmatic children. We considered that these effects might be modified by sex. These hypotheses were examined using the baseline data from a cohort of children in the Childhood Asthma Management Program (CAMP) study.

\section{METHODS}

\section{Study population}

The CAMP study is a randomised clinical trial comprising 1041 children with asthma. The trial design and methodology have been previously published. ${ }^{15}$ Inclusion criteria included: age 5-12, asthma for at least 6 months, mild to moderate asthma severity, and methacholine sensitivity with a provocative concentration $\left(\mathrm{PC}_{20}\right)$ of no more than $12.5 \mathrm{mg} / \mathrm{ml}$. Demographic data; home environment characteristics; asthma symptoms, severity, and treatment; allergy history; and relevant family history were collected at baseline. Each patient's parent or guardian signed a consent statement. All information and measures were collected at the time of randomisation, following a screening period of at least 28 days on salbutamol (albuterol) on an as needed basis only.

\section{Pulmonary function testing}

Spirometric and methacholine testing were performed on a Collins Stead-Wells dry seal Survey III spirometer. ${ }^{15}$ At least three acceptable manoeuvres meeting American Thoracic Society (ATS) standards were required, with at least two reproducible forced expiratory volume in 1 second $\left(\mathrm{FEV}_{1}\right)$ and forced vital capacity (FVC) manoeuvres within $5 \%$ of best required for each test. Airway responsiveness was performed in a standardised fashion, at least 4 hours after use of short acting bronchodilators and 24 hours after use of long acting bronchodilators. ${ }^{15}$ 


\section{Measures}

BMI was calculated from measured values of height and weight by the equation $\mathrm{BMI}=$ weight $(\mathrm{kg}) /$ height $^{2}\left(\mathrm{~m}^{2}\right)$. Pulmonary function outcomes included pre- and postbronchodilator $\mathrm{FEV}_{1}, \mathrm{FVC}, \mathrm{FEV}_{1} / \mathrm{FVC}$ ratio, and peak flow, analysed as quantitative traits. Asthma symptom outcomes were dichotomised and considered relevant as follows: school absences $(>5$, since fewer than this might be expected from non-asthma factors), emergency department visits and hospital admissions (any), doctor visits ( $>6$, since reasonable visits may be expected every other month for a healthy asthmatic), days on oral steroids ( $>7$, since up to a week's worth may be dispensed for mild asthma), physical education restriction (any reported), and cough/wheeze at rest or with exercise (>once/month over 6 months). Outcomes were based upon occurrences over past year, except steroid days (past 6 months) and cough/wheeze (monthly average over the past 6 months). Intermediate phenotypes of asthma and atopy included $\mathrm{FEV}_{1}$ change with bronchodilator and log transformations of $\mathrm{PC}_{20}$, serum IgE, and eosinophil count, evaluated in a quantitative fashion.

BMI was the primary predictor of interest. Potential confounders included clinic attended, age, race, sex, caregiver education, family income, familial asthma history, presence of environmental tobacco smoke, and participant Tanner stage. Tanner stage was defined by male genital and female breast development. BMI was modelled as a linear term, while the other potential confounders were either dichotomised or categorised into groups. Additional analyses using other surrogates of total body fat (waist circumference and waist to hip ratio) as predictors were also performed. Finally, analyses of the upper extremes of BMI were performed using age, ethnic, and sex specific BMI percentile cut offs of $85 \%$ for overweight and $95 \%$ for obese. ${ }^{16}$

\section{Statistical analysis}

Univariate and multivariable regression analyses incorporating significant potential confounders were performed. Modelling using linear regression was performed for all of the pulmonary function and intermediate phenotype outcomes. Symptom outcomes were modelled using logistic regression techniques. Height adjustment was performed for models evaluating the $\mathrm{FEV}_{1}, \mathrm{FVC}$, and peak flows. Collinearity diagnostics were performed. Potential for effect modification of sex with BMI was evaluated by use of stratified analyses and interaction terms. The assumption of linearity within the BMI predictor was assessed by dividing BMI into quintiles and looking for threshold and non-linear effects. To further evaluate the potential for the age dependency of BMI, Box-Cox transformations of age on BMI were performed. We then re-evaluated all of our models using the transformed BMI, thereby verifying our results in an a priori age adjusted fashion. Since the transformed BMI results were similar in magnitude but difficult to interpret, we have used the non-transformed, age adjusted BMI in reporting our results. All analyses were performed using the SAS statistical software package (Version 6.12, SAS Institute, Cary, NC).

\section{RESULTS}

Table 1 presents baseline descriptive data on the BMI of 1039 asthmatic children participating in the CAMP study. 123 of the children ( $11.8 \%$ ) met the criteria for obesity and a further $181(17.4 \%)$ for overweight. Overall, asthma was mild in these children, with a mean post-bronchodilator $\mathrm{FEV}_{1}$ of $102 \%$ predicted. As expected, BMI was significantly associated with measures of growth and development such as age and Tanner stage. Other significant potential confounders associated with BMI in the univariate analysis included
Table 1 Relation of BMI to selected confounders* of asthma severity in the Childhood Asthma Management Program (CAMP) population

\begin{tabular}{llll}
\hline Variable & N & Median BMI & p value \\
\hline Overall & $1039 \dagger$ & 17.09 & \\
Age (years) & & & 0.0001 \\
$5-6$ & 263 & 15.96 & \\
$7-8$ & 319 & 16.56 & \\
$9-10$ & 272 & 17.93 & \\
I1-12 & 185 & 19.60 & \\
Ethnicity & & & 0.0001 \\
White & 709 & 16.96 & \\
Black & 138 & 17.63 & \\
Hispanic & 98 & 18.77 & \\
Other & 94 & 16.55 & \\
Sex & & & 0.52 \\
Boys & 621 & 17.04 & \\
Girls & 418 & 17.19 & \\
Tanner stage & & & 0.0001 \\
I & 749 & 16.61 & \\
II & 202 & 18.10 & \\
III & 56 & 20.57 & \\
IV & 24 & 21.11 & \\
V & 3 & 24.69 & \multirow{2}{*}{0.04} \\
Parental smoking & & & \\
Neither & 746 & 16.97 & \\
Mother only & 89 & 17.30 & \\
Father only & 96 & 17.26 & \\
Both & 100 & 17.32 & \\
\hline
\end{tabular}

*Not shown are CAMP centre $(p=0.0001)$, history of parental asthma, parental educational level, and parental income (all with $p$ values $>0.20$ ).

†Baseline height not recorded for two children.

¥For within group comparisons of ranked BMI (Kruskal-Wallis test).

ethnicity, clinical centre, and presence of any parental smoking. Sex, parental income, caregiver education, and history of parental asthma were not significantly associated with BMI. Since age is closely correlated with BMI in children, we reassessed all analyses using a Box-Cox transformation of age on BMI to provide age adjusted estimates of the relationships. The results of these subsequent analyses paralleled our primary results (data not shown).

\section{Relationship between BMI and respiratory symptoms}

The relationship between BMI and reported measures of asthma severity are shown in table 2 . In the multivariable analysis only cough/wheeze with exercise was related to BMI (OR 1.05, 95\% CI 1.01 to 1.10 for more than one coughing/ wheezing episode with exercise per month over the past 6 months).

\section{Relationship between BMI and other measures of body fat and intermediate phenotypes of asthma and atopy} The four intermediate phenotypes of interest-eosinophil count, IgE level, bronchodilator response, and methacholine sensitivity-and their adjusted relationship to BMI, waist circumference, and waist to hip ratio are shown in table 3. BMI was negatively associated with bronchodilator response $(\beta=-0.003, p=0.02)$ - that is, as BMI increased, small decrements in the response to bronchodilators were noted. A higher $\mathrm{BMI}$ was also related to a higher $\log \mathrm{PC}_{20}$ (less airways reactivity). However, after adjustment for baseline levels of $\mathrm{FEV}_{1}$, this effect was no longer seen. Neither of the measures of atopy (IgE and eosinophil count) was significantly associated with BMI. No consistent relationship between the measures of body fat (BMI, waist circumference, and waist to hip ratio) and any of the intermediate phenotype outcomes was noted. 
Table 2 Relationship between BMl and asthma symptom outcomes

\begin{tabular}{lllll}
\hline Outcomet & $\begin{array}{l}\text { Crude odds ratio } \\
(95 \% \mathrm{CI})\end{array}$ & p value & $\begin{array}{l}\text { Adjusted* odds ratio } \\
(\mathbf{9 5 \%} \mathrm{Cl})\end{array}$ & p value \\
\hline School absence & $1.01(0.97$ to 1.05$)$ & 0.67 & $1.01(0.96$ to 1.05$)$ & 0.77 \\
Emergency room visits & $1.02(0.98$ to 1.06$)$ & 0.25 & $1.02(0.98$ to 1.07$)$ & 0.36 \\
Hospital admissions & $0.99(0.91$ to 1.08 & 0.84 & $0.95(0.86$ to 1.05$)$ & 0.33 \\
Visits to doctor & $1.04(0.99$ to 1.09$)$ & 0.06 & $1.00(0.95$ to 1.05$)$ & 0.90 \\
Days on steroids & $1.03(0.98$ to 1.09$)$ & 0.23 & $1.01(0.95$ to 1.07$)$ & 0.87 \\
Physical education restriction & $0.97(0.92$ to 1.02$)$ & 0.19 & $0.99(0.93$ to 1.05$)$ & 0.72 \\
Cough/wheeze at rest & $1.02(0.99$ to 1.06$)$ & 0.21 & $1.03(0.99$ to 1.07$)$ & 0.22 \\
Cough/wheeze with exercise & $1.05(1.01$ to 1.09$)$ & 0.02 & $1.05(1.01$ to 1.10$)$ & 0.03 \\
\hline
\end{tabular}

*Adjusted for age, race, sex, clinic, Tanner stage, and parental smoking.

†Outcomes based on occurrences over past year, except steroid days (past 6 months) and cough/wheeze (monthly average over the past 6 months). The outcomes were dichotomised at the following levels: school absences $(\leqslant 5 v>5)$, ER visits and hospital admissions (none $v$ any), visits to doctor $(\leqslant 6 v>6)$, days on steroids $(\leqslant 7 v>7)$, physical education restriction (none $v$ any), and cough/wheeze $(\leqslant 1 \quad v>1)$.

\section{Relationship between BMI and pulmonary function}

Table 4 shows the post-bronchodilator multivariable relationship between BMI and pulmonary function outcomes. BMI was positively associated with spirometric measurements including $\mathrm{FEV}_{1}, \mathrm{FVC}$, and peak flow. Pre-bronchodilator trends were similar (data not shown). The strongest relationships were noted for FVC. Specifically, an increase in BMI of 5 units (as would occur between normal weight and obesity) was associated with a gain in FVC of slightly more than $60 \mathrm{ml}$. Increases in BMI were thus associated with increased spirometric pulmonary function. In contrast, significant decrements in the $\mathrm{FEV}_{1} / \mathrm{FVC}$ ratio were noted in association with increasing BMI ( $p$ for trend for boys $=0.002$; fig 1 ).

The strength of the BMI effects on pulmonary function seemed to vary when stratified by sex. Although the direction of the effect was the same for both sexes, the association with BMI was significant only in girls in relation to the $\mathrm{FEV}_{1}$, change in $\mathrm{FEV}_{1}$ with bronchodilator, and $\log \mathrm{PC}_{20}$ (table 4). The relationship between BMI and both pre- and postbronchodilator FVC was also stronger in girls than in boys. However, the $\mathrm{FEV}_{\mathrm{l}} / \mathrm{FVC}$ ratio decrements with increasing BMI were more substantial in boys. Univariate analysis of the relationship between sex and the potential confounders of pulmonary function was performed. There were no significant differences between boys and girls with regard to height, ethnicity, age, parental smoking, or clinic. The addition of interaction terms to models evaluating sex and BMI as predictors of pulmonary function outcomes did not show a significant interaction between sex and BMI in any of the multivariable models tested (data not shown).

\section{BMI quintile analysis}

Age adjusted BMI quintile analysis was performed (fig 2). For both boys and girls spirometric measures $\left(\mathrm{FEV}_{\mathrm{l}}, \mathrm{FVC}\right.$, and peak flow) increased in a linear fashion as the BMI quintile increased. No significant within group differences were noted for either bronchodilator response or $\mathrm{PC}_{20}$. Overall, no overt threshold effects were noted. Modelling BMI as a linear predictor of pulmonary function therefore seems reasonable. Moreover, while the results of obesity specific analyses paralleled our other results, the lack of a threshold suggests that the extremes of weight did not have a unique association with our outcomes. No results of obesity specific analyses are therefore presented.

\section{DISCUSSION}

The overall magnitude and direction of the associations seen do not support the hypothesis that increasing BMI significantly contributes to overall asthma severity in a large cross sectional population of children with mild to moderate asthma. In general, increasing body mass was correlated with increasing spirometric values and was not associated with asthma symptoms. The notable exception to this was the association of increasing BMI with decrements in the $\mathrm{FEV}_{\mathrm{l}} / \mathrm{FVC}$ ratio. The relationship between BMI and the intermediate phenotypes of asthma evaluated, however, were less clear. While measures of atopy were not correlated with BMI, we did find a significant relationship between BMI and two common intermediate phenotypes of asthma-change in $\mathrm{FEV}_{1}$ with bronchodilator and degree of methacholine sensitivity. However, no significant relationship between $\mathrm{BMI}$ and $\mathrm{PC}_{20}$ remained after adjustment for baseline $\mathrm{FEV}_{1}$, suggesting that this effect may have been driven by underlying airways size. This was further supported by the lack of association between these measures of airway responsiveness and waist circumference and waist to hip ratio.

Previous population based studies of children have reported increases in spirometric measurements with increases in body weight and BMI. In calculating reference values for $\mathrm{FEV}_{1}$ and FVC, however, early studies concluded that adjustment for weight was unnecessary because the

Table 3 Relationship between measures of body fat and markers of asthma and atopy*

\begin{tabular}{|c|c|c|c|c|c|c|}
\hline & $\begin{array}{l}\text { BMI }\left(\mathrm{kg} / \mathrm{m}^{2}\right) \\
\beta(95 \% \mathrm{Cl})\end{array}$ & p value & $\begin{array}{l}\text { Waist }(\mathrm{cm}) \\
\beta(95 \% \mathrm{Cl})\end{array}$ & p value & $\begin{array}{l}\text { Waist to hip ratio } \\
\beta(95 \% \mathrm{Cl})\end{array}$ & $\mathrm{p}$ value \\
\hline Log eosinophil† & $-0.017(-0.036$ to 0.001$)$ & 0.06 & $-0.011(-0.017$ to 0.005$)$ & 0.0009 & $-0.51(-1.470$ to 0.456$)$ & 0.30 \\
\hline Log lgE† & $-0.028(-0.059$ to 0.002$)$ & 0.07 & $-0.005(-0.016$ to 0.061$)$ & 0.38 & $-0.29(-1.933$ to 1.359$)$ & 0.73 \\
\hline $\mathrm{BD}$ changef & $-0.003(-0.001$ to -0.004$)$ & 0.02 & $-0.0007(-0.014$ to 0$)$ & 0.06 & $0.047(-0.064$ to 0.158$)$ & 0.41 \\
\hline $\log \mathrm{PC}_{20}{ }^{+}$ & $0.034(0.012$ to 0.057$)$ & 0.003 & $0.007(0.002$ to 0.015$)$ & 0.11 & $-0.037(-0.933$ to 0.859$)$ & 0.95 \\
\hline $\begin{array}{l}\log \mathrm{PC}_{20}\left(\mathrm{FEV}_{1}\right. \\
\text { adjusted) } \dagger\end{array}$ & $0.006(-0.017$ to 0.028$)$ & 0.64 & $-0.005(-0.014$ to 0.003$)$ & 0.21 & $0.0004(-1.195$ to 1.195$)$ & 0.99 \\
\hline
\end{tabular}

*Adjusted for age, race, sex, clinic, Tanner stage, and parental smoking

†Natural log.

$\ddagger$ Bronchodilator (BD) change defined as change in $\mathrm{FEV}_{1}$ with bronchodilator divided by initial $\mathrm{FEV} \mathrm{V}_{1}$. 
Table 4 Relationship between BMI and spirometric parameters and airway responsiveness*

\begin{tabular}{|c|c|c|c|c|c|c|}
\hline \multirow[b]{2}{*}{ Outcome } & \multicolumn{2}{|l|}{ Overall } & \multicolumn{2}{|l|}{ Boys } & \multicolumn{2}{|l|}{ Girls } \\
\hline & $\beta(95 \% \mathrm{Cl})$ & $p$ value & $\beta(95 \% \mathrm{Cl})$ & $p$ value & $\beta(95 \% \mathrm{Cl})$ & p value \\
\hline \multicolumn{7}{|l|}{ Post-BD } \\
\hline $\mathrm{FEV}_{1}(\mathrm{l}) \dagger$ & $0.006(0.001$ to 0.010$)$ & 0.01 & $0.003(-0.003$ to 0.009$)$ & 0.32 & $0.008(0.004$ to 0.012$)$ & 0.02 \\
\hline FVC (I)† & $0.012(0.007$ to 0.017$)$ & 0.0001 & $0.009(0.002$ to 0.016$)$ & 0.009 & $0.014(0.006$ to 0.021$)$ & 0.0004 \\
\hline $\mathrm{FEV}_{1} / \mathrm{FVC}$ & $-0.242(-0.118$ to -0.366$)$ & 0.0001 & $-0.297(-0.127$ to -0.467$)$ & 0.0006 & $-0.188(-0.001$ to -0.375$)$ & 0.05 \\
\hline Peak flow $(\mathrm{l} / \mathrm{min}) \dagger$ & $0.230(-0.674$ to 1.14$)$ & 0.61 & $0.149(-1.127$ to 1.425$)$ & 0.82 & $0.640(-0.717$ to 1.987$)$ & 0.36 \\
\hline $\mathrm{BD}$ change & $-0.003(-0.001$ to -0.004$)$ & 0.02 & $-0.001(-0.004$ to 0.002$)$ & 0.37 & $-0.003(-0.001$ to -0.006$)$ & 0.02 \\
\hline $\log \mathrm{PC}_{20}$ & $0.034(0.012$ to 0.057$)$ & 0.003 & $0.021(-0.008$ to 0.054$)$ & 0.18 & $0.043(0.008$ to 0.078$)$ & 0.02 \\
\hline
\end{tabular}

*Adjusted for age, race, sex, clinic, Tanner stage, and parental smoking.

†Also adjusted for height.

$\mathrm{B}$ Bronchodilator $(\mathrm{BD})$ change defined as change in $\mathrm{FEV}_{1}$ with bronchodilator divided by initial $\mathrm{FEV} \mathrm{V}_{1}$.

additional explained variance was small after adjustment for height, sex, and race. ${ }^{17}{ }^{18}$ Lazarus et al ${ }^{19}$ reported a much larger positive association of weight with height adjusted FEV $_{1}$ and FVC in a cross sectional study of normal schoolchildren. However, they subsequently found decreases in height and weight adjusted spirometric measures with increasing skinfold thicknesses, concluding that an increased BMI in children may not adequately distinguish increased lean tissue mass from increased fat mass. Fung et $a^{20}$ also noted increased spirometric flows correlating to increased BMI in a population of Chinese schoolchildren. Nevertheless, overweight children ( $>90 \%$ predicted) had decrements in these pulmonary measures in association with increasing BMI, supporting other studies which noted a classic restrictive ventilatory defect in obese children. ${ }^{21}$ In contrast, only one of our subjects had an age adjusted BMI in excess of $150 \%$ of predicted. Any expected decline in spirometric parameters due to large increases in fat mass would not therefore have been powered to be detected in our study. Overall, our data suggest that the small but significant increases in $\mathrm{FEV}_{1}$ and FVC seen in normal children in association with increases in BMI are also present in children with mild to moderate asthma (table 4, fig 2).

Although airway responsiveness (AHR) has recently been correlated with asthma severity in children, ${ }^{22}$ little is known about the relationship between BMI and intermediate phenotypes of asthma, including measures of atopy, AHR, and bronchodilator response. In a cross sectional population based study of teenagers in Taiwan, Huang et $a^{23}$ noted a decreased prevalence of AHR in the lowest quintile of BMI in teenage girls and increased atopy in girls with the highest

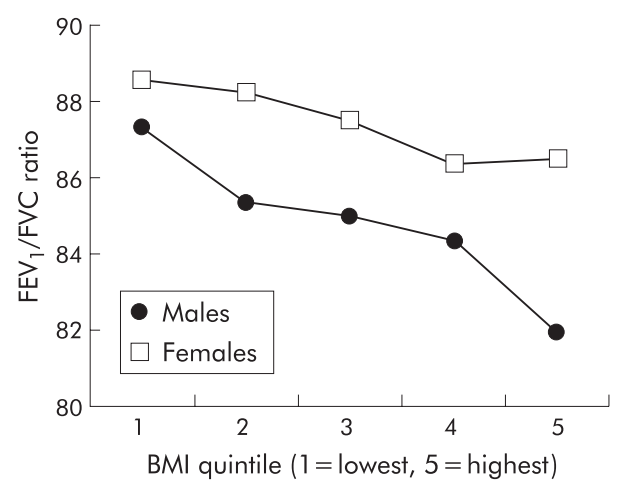

Figure 1 Median post-bronchodilator $\mathrm{FEV}_{1} / \mathrm{FVC}$ ratio across age adjusted BMI quintiles after Box-Cox transformation of age on BMI. In both sexes increases in $\mathrm{BMI}$ are associated with decrements in the $\mathrm{FEV}_{1} /$ FVC ratio. This effect was more pronounced in boys ( $p$ for trend $=0.002$ ).
BMI. These findings were not seen in boys. While other studies have not noted any independent effect of BMI on methacholine sensitivity, ${ }^{24}{ }^{25}$ the consistent association of obesity with exercise induced bronchospasm in children ${ }^{26} 27$ has suggested a relationship between increased AHR and BMI. Although our cohort of asthmatic children differed from the above, the initial finding of a positive association between $\mathrm{PC}_{20}$ and $\mathrm{BMI}$ was still somewhat puzzling. However, this effect was not found when the regression was adjusted for airway size, nor was it seen with other measures of body fat (table 3). Similarly, none of the other intermediate phenotypes were consistently associated with any of the proxies for body fat mass.

The exact reason why the relationship between BMI and pulmonary function would be stronger in one sex in our study population (table 4) is unknown. However, this prepubertal relationship can be most readily explained by differential airways size. Throughout childhood girls have larger airways in relation to lung size than boys, a phenomenon that begins to reverse in adolescence. ${ }^{28}$ While airway size can help to explain the differential spirometric values noted in our study, smaller airway calibre has also been used to explain the increased AHR in adult women. ${ }^{29}$ Similarly, the findings of decreased AHR and bronchodilator responsiveness in the girls relative to the boys in our study may be simply related to differential airway calibre.

We cannot exclude the possibility that differences in sample size between the boys and girls in our study could account for our finding that decrements in $\mathrm{FEV}_{\mathrm{l}} / \mathrm{FVC}$ ratio noted with increasing BMI were more prominent in the CAMP boys (fig 1); however, differences in airway size between boys and girls may also play a role. The $\mathrm{FEV}_{1} / \mathrm{FVC}$ ratio is commonly used as a measure of the degree of airflow

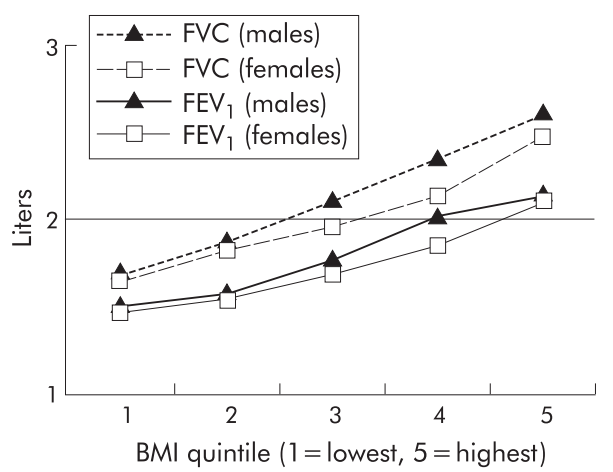

Figure 2 Relationship between median post-bronchodilator $\mathrm{FEV}_{1}$ and FVC and age adjusted BMI quintiles. Spirometric measures increased linearly across the BMI quintiles in both boys and girls. 
obstruction and severity of asthma. While ratio measures are described in few population based studies of paediatric lung function, in young children overall measures of airflow to FVC are decreased in boys compared with girls ${ }^{30} 31$ and in asthmatics compared with non-asthmatics. ${ }^{12}$ Increasing BMI correlated with decreasing $\mathrm{FEV}_{\mathrm{l}} / \mathrm{FVC}$ ratio in one other population based study of paediatric spirometry. ${ }^{32}$ This association was also greater in boys. While the presence of asthma in that study did not appear to affect the relationship between BMI and $\mathrm{FEV}_{1} / \mathrm{FVC}$ ratio, only $7 \%$ of these children reported a diagnosis of asthma, probably resulting in insufficient power for detection. Whether these differences help to explain the increased incidence of asthmatic symptoms in prepubertal boys requires further study.

While we found that many of the effects noted were stronger in one sex, analyses failed to note a significant interaction between sex and BMI. It is likely, given the modest effects noted as well as the parallel direction of the effects within each sex, that a larger sample size or sicker patient population could have resulted in significant interaction terms.

The overall direction and magnitude of the relationships between BMI and the outcomes of interest in this study do not support a significant detrimental association between increasing BMI and asthma severity in children. The potential reasons for this departure from our hypothesised relationships are several. Firstly, our source population, a cohort of children with pre-existing asthma, differs from the general population based cohorts used in the incidence ${ }^{314}$ and prevalence $^{4-7}$ studies associating asthma and BMI. Moreover, comparisons of within group phenotypes are not comparable to studies evaluating differences between asthmatic and normal subjects. The strict entry criteria for this clinical trial ${ }^{15}$ may also not have provided enough variability in the outcomes of interest to detect differences in our predictor of interest. Previous studies of asthma symptoms have used primarily inner city subjects, ${ }^{33}{ }^{34}$ a population which contrasts with that of the CAMP children. ${ }^{15}$ Additionally, many of these previous studies focused on obesity and asthma. Only one of the children enrolled in CAMP had a baseline BMI in excess of $150 \%$ of predicted for age. Thus, any potential associations due to extremes of BMI would not have been adequately powered within our cohort. In this study, BMI was modelled as our primary surrogate of total body fat. The usefulness of this measure in children has been criticised. ${ }^{19}$ The best epidemiological measure of body fat in children and adolescents remains controversial, ${ }^{35}$ but may be one using skinfold measures which were not assessed in CAMP. Hence, BMI used as a primary predictor may not have adequately distinguished between large children and obese ones. Finally, in a previous study of incident asthma in children, asthma risk was inversely related to Tanner stage in boys (RR 0.3 for stage V compared with stage I) but positively related to Tanner stage in girls (RR 1.6 for stage V compared with stage I). ${ }^{3}$ If puberty is highly correlated with any of our outcomes of interest, our study may not have been powered to detect these associations. The report of a much stronger association between BMI and the prevalence of asthma in children over 10 years of age compared with younger children $^{8}$ lends support to this possibility. Over $90 \%$ of our cohort were Tanner stages I or II, and less than 3\% were stages IV or V at baseline assessment.

Our study also suffers from the limitations common to cross sectional studies. Certainly the association between BMI and pulmonary function cannot demonstrate causality or even the direction of the relationship. One could infer that children with higher $\mathrm{FEV}_{1}$ and FVC levels are more apt to eat more and therefore increase their BMI or, equally, that BMI levels directly alter levels of pulmonary function.
Longitudinal studies within a cohort of asthmatic subjects are necessary to help clarify this relationship.

In conclusion, we have noted changes in spirometric pulmonary function related to BMI in a cohort of asthmatic children. BMI at baseline, however, was not prominently related to respiratory symptomatology or to any of four prominent intermediate phenotypes of asthma and atopy. Although these findings do not support our original hypothesis, the discovery of a decrement in the $\mathrm{FEV}_{1} / \mathrm{FVC}$ ratio in association with increasing BMI suggests that a significant relationship may yet exist. Further studies evaluating specific aspects of the BMI/asthma relationship are warranted. Such studies evaluating change in BMI over time, extremes of body mass effects, or sex specific pubertal changes on this relationship may provide further insights into the pathogenesis and treatment of childhood asthma.

\section{ACKNOWLEDGEMENT}

The Childhood Asthma Management Program is supported by contracts NOl-HR-16044, 16045, 16046, 16047, 16048, 16049, 16050,16051 , and 16052 with the National Heart, Lung, and Blood Institute and General Clinical Research Center grants M01RR00051, M0lRR0099718-24, M0IRR02719-14, and RR00036 from the National Center for Research Resources.

Dr Tantisira is supported by NIH: 2T32 HL07427, Clinical Epidemiology of Lung Diseases, Dr Litonjua is supported by a Mentored Clinical Scientist Development Award: KO8-HL03870, and Dr Fuhlbrigge is supported by a Mentored Clinical Scientist Development Award: KO8 HL03919-01, from the National Heart, Lung, and Blood Institute.

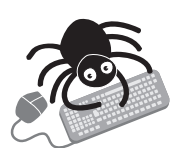

Members of the CAMP Research Group are available on the Thorax website at www.thoraxjnl.com/ supplemental.

\section{Authors' affiliations}

K G Tantisira, A A Litonjua, S T Weiss, A L Fuhlbrigge, Channing Laboratory, Department of Medicine, Brigham and Women's Hospital and Harvard Medical School, Boston, MA 02115, USA

Funding: The Childhood Asthma Management Program is supported by contracts NO1-HR-16044, 16045, 16046, 16047, 16048, 16049 16050,16051 , and 16052 with the National Heart, Lung, and Blood Institute and General Clinical Research Center grants M01RR00051, M01RR0099718-24, M01RR02719-14, and RR00036 from the National Center for Research Resources.

\section{REFERENCES}

1 Division of Health Examination Statistics, National Center for Health Statistics, Division of Nutrition and Physical Activity, National Center for Chronic Disease Prevention and Health Promotion, CDC. Update: Prevalence of overweight among children, adolescents, and adults-United States, 19881994. MMWR 1997;46:199-202.

2 Mannino DM, Homa DM, Pertowski CA, et al. Surveillance for asthmaUnited States, 1960-1995. MMWR 1998:47:1-28.

3 Camargo CA Jr, Field AE, Colditz GA, et al. Body mass index and asthma in children aged 9-14. Am J Respir Crit Care Med 1999;159:A150.

4 Figueroa-Munoz JI, Chinn S, Rona RJ. Association between obesity and asthma in 4-11 year old children in the UK. Thorax 2001;56:133-7.

5 Epstein LH, Wu YW, Paluch RA, et al. Asthma and maternal body mass index are related to pediatric body mass index and obesity: results from the Third National Health and Nutrition Examination Survey. Obes Res 2000;8:575-81.

6 Gold DR, Rotnitzky A, Doamokosh Al, et al. Race and gender differences in respiratory illness prevalence and their relationship to environmental exposures in children 7 to 14 years of age. Am Rev Respir Dis 1993; 148:10-18.

7 Lee SI, Shin MH, Lee HB, et al. Prevalences of symptoms of asthma and other allergic diseases in korean children: a nationwide questionnaire survey. J Korean Med Sci 2001;16:155-64.

8 Rodriguez MA, Winkleby MA, Ahn D, et al. Identification of population subgroups of children and adolescents with high asthma prevalence: findings from the third national health and nutrition examination survey. Arch Pediatr Adolesc Med 2002; 156:269-75. 
9 Gennuso J, Epstein LH, Paluch RA, et al. The relationship between asthma and obesity in urban minority children and adolescents. Arch Pediatr Adolesc Med 1998;152:1197-200.

10 Martinez FD, Wright AL, Taussig LM, et al. Asthma and wheezing in the first six years of life. The Group Health Medical Associates. N Engl J Med 1995;332:133-8.

11 Meurer JR, George V, Subichin S, et al. Asthma severity among children hospitalized in 1990 and 1995. Arch Pediatr Adolesc Med 2000;154: 143-9.

12 Gold DR, Wypii D, Wang X, et al. Gender- and race-specific effects of asthma and wheeze on level and growth of lung function in children in six US cities. Am J Respir Crit Care Med 1994; 149: 1198-208.

13 von Kries R, Hermann M, Grunert VP, et al. Is obesity a risk factor for childhood asthma? Allergy 2001;56:318-22.

14 Castro-Rodriguez JA, Holberg CJ, Morgan WJ, et al. Increased incidence of asthmalike symptoms in girls who become overweight or obese during the school years. Am J Respir Crit Care Med 2001;163:1344-9.

15 Childhood Asthma Management Program Research Group. The Childhood Asthma Management Program (CAMP): design, rationale, and methods. Control Clin Trials 1999:20:91-120.

16 Rosner B, Prineas R, Loggie J, et al. Percentiles for body mass index in US children 5 to 17 years of age. J Pediatr 1998;132:21 1-22.

17 Dockery D, Berkey CS, Ware J, et al. Distribution of forced vital capacity and forced expiratory volume in one second in children 6 to 11 years of age. Am Rev Respir Dis 1983;128:405-12.

18 Schwartz J, Katz S, Fegley R, et al. Analysis of spirometric data from a national sample of healthy 6- to 24-year-olds (NHANES II). Am Rev Respir Dis 1988;138:1405-14.

19 Lazarus R, Colditz G, Berkey CS, et al. Effects of body fat on ventilatory function in children and adolescents: cross-sectional findings from a random population sample of school children. Pediatr Pulmonol 1997;24:187-94.

20 Fung KP, Lau SP, Chow OK, et al. Effects of overweight on lung function. Arch Dis Child 1990:65:512-5.

21 Inselman LS, Milanese A, Deurloo A. Effect of obesity on pulmonary function in children. Pediatr Pulmonol 1993;16:130-7.

22 Weiss ST, Van Natta ML, Zeiger RS. Relationship between increased airway responsiveness and asthma severity in the Childhood Asthma Management Program. Am J Respir Crit Care Med 2000;162:50-6.
23 Huang SL, Shiao G, Chou P. Association between body mass index and allergy in teenage girls in Taiwan. Clin Exp Allergy 1999;29:323-9.

24 Rasmussen F, Lambrechtsen J, Siersted HC, et al. Low physical fitness in childhood is associated with the development of asthma in young adulthood: the Odense schoolchild study. Eur Respir J 2000;16:866-70.

25 Schachter LM, Salome CM, Peat JK, et al. Obesity is a risk for asthma and wheeze but not airway hyperresponsiveness. Thorax 2001;56:4-8.

26 Kaplan TA, Montana E. Exercise-induced bronchospasm in nonasthmatic obese children. Clin Pediatr (Phila) 1993;32:220-5

27 del Rio-Navarro B, Cisneros-Rivero M, Berber-Eslava A, et al. Exercise induced bronchospasm in asthmatic and non-asthmatic obese children. Allergol Immunopathol (Madr) 2000;28:5-11.

28 Becklake MR, Kauffmann F. Gender differences in airway behaviour over the human life span. Thorax 1999;54:1119-38.

29 De Marco R, Locatelli F, Sunyer J, Burney P, the European Community Respiratory Health Survey Study Group. Differences in incidence of reported asthma related to age in men and women. A retrospective analysis of the data of the European Respiratory Health Survey. Am J Respir Crit Care Med 2000;162:68-74.

30 Wang $\mathrm{X}$, Dockery DW, Wypii D, et al. Pulmonary function between 6 and 18 years of age. Pediatr Pulmonol 1993;15:75-88.

31 Rosenthal M, Cramer D, Bain SH, et al. Lung function in white children aged 4 to 19 years: II. Single breath analysis and plethysmography. Thorax 1993:48:803-8.

32 Pistelli $R$, Brancato $G$, Forastiere $F$, et al. Population values of lung volumes and flows in children: effect of sex, body mass and respiratory conditions. Eur Respir J 1992;5:463-70; erratum 1992;5:904.

33 Luder E, Melnik TA, DiMaio M. Association of being overweight with greater asthma symptoms in inner city black and Hispanic children. J Pediatr 1998; 132:699-703.

34 Belamarich PF, Luder E, Kattan M, et al. Do obese inner-city children with asthma have more symptoms than nonobese children with asthma? Pediatrics 2000;106:1436-41

35 Sangi $H$, Mueller WH. Which measure of body fat distribution is best for epidemiologic research among adolescents? Am J Epidemiol $1991 ; 133: 870-83$

\section{LUNG ALERT}

\section{Factors associated with physicians' decisions to withdraw mechanical ventilation in anticipation of death}

$\Delta$ Cook D, Rocker G, Marshall J, et al. Withdrawal of mechanical ventilation in anticipation of death in the intensive care unit. N Engl J Med 2003;349:1123-32

- ight hundred and fifty one consecutive patients mechanically ventilated for at least 72

- hours in intensive care units in 15 different centres were prospectively followed. The

- relation between various factors and withdrawal of mechanical ventilation was assessed using Cox proportional hazards analysis.

Ventilation was withdrawn in $19.5 \%$ of the original cohort. Four factors were identified as being associated with withdrawal of ventilation: use of inotropes and vasopressors (hazard ratio $1.78, \mathrm{p}=0.004$ ), physician's prediction of a less than $10 \%$ chance of survival (hazard ratio $3.49, \mathrm{p}=0.002$ ) and of severely impaired future cognitive function (hazard ratio 2.51, $\mathrm{p}=0.04$ ), and the physician's perception that the patient did not want life support (hazard ratio $4.19, \mathrm{p}<0.001$ ).

Physicians' perceptions and predictions formed the majority of factors in this study, which extends our understanding of the process of withdrawal of life support and questions the traditional biomedical model used (age and severity of illness or organ dysfunction were not factors). It is encouraging that one of the key factors was the wishes of the patients, but these might not be accurately reflected by relatives or physicians. Further research is required to clarify this issue.

A R L Medford

Clinical Research Fellow and Honorary Specialist Registrar, University of Bristol, Southmead Hospital, Bristol, UK andrew.medford@bristol.ac.uk 